\title{
Effect of mindfulness-based stress reduction on sleep quality \\ Results of a randomized trial among Danish breast cancer patients
}

Andersen, Signe R.; Würtzen, Hanne; Steding-Jessen, Marianne; Christensen, Jane; Andersen, Klaus K.; Flyger, Henrik; Mitchelmore, Cathy; Johansen, Christoffer; Dalton, Susanne O.

Published in:

Acta Oncologica

Publication date:

2013

Document Version

Early version, also known as pre-print

Citation for published version (APA):

Andersen, S. R., Würtzen, H., Steding-Jessen, M., Christensen, J., Andersen, K. K., Flyger, H., Mitchelmore, C., Johansen, C., \& Dalton, S. O. (2013). Effect of mindfulness-based stress reduction on sleep quality: Results of a randomized trial among Danish breast cancer patients. Acta Oncologica, 52, 336-344.

\section{General rights}

Copyright and moral rights for the publications made accessible in the public portal are retained by the authors and/or other copyright owners and it is a condition of accessing publications that users recognise and abide by the legal requirements associated with these rights.

- Users may download and print one copy of any publication from the public portal for the purpose of private study or research.

- You may not further distribute the material or use it for any profit-making activity or commercial gain.

- You may freely distribute the URL identifying the publication in the public portal.

Take down policy

If you believe that this document breaches copyright please contact rucforsk@kb.dk providing details, and we will remove access to the work immediately and investigate your claim. 


\title{
Effect of mindfulness-based stress reduction on sleep quality: Results of a randomized trial among Danish breast cancer patients
}

\author{
SIGNE R. ANDERSEN ${ }^{1}$, HANNE WÜRTZEN ${ }^{1}$, MARIANNE STEDING-JESSEN $^{2}$, \\ JANE CHRISTENSEN ${ }^{2}$, KLAUS K. ANDERSEN ${ }^{2}$, HENRIK FLYGER ${ }^{3}$, \\ CATHY MITCHELMORE ${ }^{4}$, CHRISTOFFER JOHANSEN ${ }^{1} \&$ SUSANNE O. DALTON $^{1}$ \\ ${ }^{1}$ Danish Cancer Society Research Center, Survivorship, Copenhagen, Denmark, ${ }^{2}$ Danish Cancer Society \\ Research Center, Biostatistics, Bioinformatics and Registry, Copenhagen, Denmark, ${ }^{3}$ University Hospital Herlev, \\ Department of Breast Surgery, Herlev, Denmark and ${ }^{4}$ Roskilde University, Department of Science, Systems and \\ Models, Roskilde, Denmark
}

\begin{abstract}
The prevalence of sleep disturbance is high among cancer patients, and the sleep problems tend to last for years after the end of treatment. As part of a large randomized controlled clinical trial (the MICA trial, NCT00990977) of the effect of mindfulness-based stress reduction (MBSR) on psychological and somatic symptoms among breast cancer patients, the aim of the current study was to evaluate the effect of MBSR on the secondary outcome, 'sleep quality'. Material and methods. A total of 336 women operated on for breast cancer stage I-III 3-18 months previously were randomized to MBSR $(\mathrm{n}=168)$ or treatment as usual $(\mathrm{n}=168)$; both groups received standard clinical care. The intervention consisted of an eight-week MBSR program (psycho-education, meditation and gentle yoga). Sleep quality was assessed on the Medical Outcome Study sleep scale at baseline, after the intervention and at six- and 12-months' follow-up. Results. The mean sleep problem scores were significantly lower in the MBSR group than in controls immediately after the intervention. Quantile regression analyses showed that the effect was statistically significant only for the participants represented by the lower percentile of change between baseline and post-intervention, i.e. those who had more sleep problems; the MBSR group had a significantly smaller increase in sleep problems than the control group. After the 12-month follow-up, there was no significant between-group effect of MBSR on sleep quality in intention-to-treat analyses. Conclusion. MBSR had a statistically significant effect on sleep quality just after the intervention but no long-term effect among breast cancer patients. Future trials in which participation is restricted to patients with significant sleep problems are recommended for evaluating the effect of MBSR on sleep quality.
\end{abstract}

Breast cancer is the commonest cancer diagnosis among women in northern European countries [1]. The treatment of breast cancer and consequently the prognosis have improved during the past few decades. As a result, an increasing number of women are long-term breast cancer survivors, of whom a considerable proportion continues to experience an array of long-term sequelae [2]. Sleep problems are highly prevalent among cancer patients, occurring in 30$50 \%$ [3], and the prevalence has been found to be higher in breast cancer patients than in those with other cancers $[4,5]$. Breast cancer patients have a high prevalence of sleep problems, especially insomnia, shortly after diagnosis, during treatment and sometimes years after the end of treatment [6-8]. Sleep problems have been associated with poor physical and mental well-being [4,9]. In spite of the high prevalence of chronic insomnia, which rarely goes into spontaneous remission, the sleep problems of cancer patients are often not treated $[4-6,10]$. Cancer patients prefer non-pharmacological treatments for sleep problems [11], increasing the demand for rigorous trials evaluating non-pharmacological interventions on sleep problems among cancer patients.

Mindfulness-based stress reduction (MBSR) is an intervention that is being evaluated increasingly for cancer patients. The MBSR program was developed

Correspondence: Hanne Würtzen, Danish Cancer Society Research Center, Survivorship, Strandboulevarden 49, DK-2100 Copenhagen, Denmark. Tel: + 45 25 357500. Fax: + 4535271811 . E-mail hannewur@cancer.dk 
by John Kabat-Zinn at the University of Massachusetts Medical School (USA), inspired by Buddhist philosophy [12]. Mindfulness is characterized by moment-to-moment awareness. The aim of mindfulness practice is to make participants more resistant to stressful events, and it provides a generic strategy for coping with a range of symptoms, such as stress and pain. Practising mindfulness increases the ability to observe thoughts, feelings and bodily sensations without judging them or trying to change them. The person learns to let go, instead of identifying him- or herself with negative emotions and sensations [12].

A meta-analysis of studies of mindfulness-based therapy among cancer patients showed clear effects on mental health, such as reduced anxiety and depression [13]. Only a few studies have assessed whether MBSR affects sleep quality, and even fewer have evaluated the impact on the sleep quality of cancer patients, with contradictory results [14-16]. Previous studies have shown that MBSR decreased distress and hot flushes $[17,18]$, and these factors have been reported by breast cancer patients to impair their sleep quality [6].

The aim of this study was to determine the effect of the MBSR program on sleep quality among breast cancer patients. Further we hypothesized that MBSR would improve sleep quality by decreasing distress and hot flushes.

\section{Methods \\ Participants}

A total of 336 women aged 18-75 years in whom breast cancer stages I-III had been diagnosed within the previous 3-18 months and who had undergone surgery for their cancer at Herlev and Ringsted hospitals were included in the population-based randomized controlled trial (MICA, NCT00990977). Women with a diagnosis of cancer within the previous 10 years, ongoing treatment for major psychiatric disease, severe medical conditions that would prevent participation in the intervention or inability to speak or write sufficient Danish were excluded. Further presentation of the sample is found elsewhere [19]. Patients were evaluated at baseline, but no criteria regarding selfreported symptoms were applied. Patients gave informed consent and filled out baseline questionnaires before the randomization procedure, and were randomized $1: 1$ by a computer program, with equal numbers of participants in the intervention $(n=168)$ and control group $(n=168)$. The intervention participants were placed in 10 MBSR groups, with 10-30 women in each group.

\section{Intervention}

The MBSR intervention used in the trial adhered to the standardized MBSR manual [12] with no further focus on sleep problems. The groups met for eight weekly two-hour sessions, with psycho-education on stress responses, mindfulness meditation (i.e. body scan, sitting and walking meditation) and gentle yoga. The women participated in a five-hour silent retreat after week 7 and were advised to practice at home for 45 minutes daily. The participants were given written material and CDs with meditation guides to support home training.

The MBSR courses were led by three clinical psychologists who were trained mindfulness instructors. Adherence to the original MBSR program was validated by a senior MBSR instructor.

\section{Measures}

Sleep quality. Sleep quality was assessed on the validated Medical Outcome Study sleep scale, which consists of 12 questions [20]. The outcomes can be evaluated from seven subscales and two overall indexes. Scoring of items is standardized, with scores in the range of 0-100 for all measures except sleep quantity items. 'Sleep quantity' denotes the hours of sleep per night, and 'optimal sleep' is scored on a dichotomous $0-1$ scale, based on whether a person slept 7-8 hours per night, which is considered to be optimal $[20,21]$. In general, a high score indicates a higher level of the item measured. 'Sleep problem index II' is an overall index covering sleep disturbance, sleep adequacy, awakening with shortness of breath or headache, and daytime somnolence. Cronbach's $\alpha$ coefficients for these multiple item sleep subscales were in the range $0.76-0.86$, confirming the internal consistency of the scale in this study.

Psychological distress. We used the global severity index from the validated symptom checklist-90-revised (SCL-90-R) to assess psychological distress [22]. This checklist consists of 90 items reflecting psychological problems and symptoms of psychopathology. The index is the average score for the 90 symptom items, and a higher score reflects greater distress.

Hot flushes. A validated hot flush score was used, which sums the frequency and severity of hot flushes [23]. The respondent is asked to report how many mild, moderate, severe or very severe hot flushes she had during the past 24 hours. One point is given for each mild hot flush, two for each moderate hot flush, three for each severe hot flush and four points for each very severe hot flush. The total hot flush score is calculated as the sum of all the points; hence, a higher score indicates more problems with hot flushes. 


\section{Statistical analyses}

To analyse differences in mean sleep subscale score between the MBSR and control groups, Student t-test was used. The analysis was repeated for each time: baseline, post-intervention and six- and 12-months' follow-up. The mean change between baseline and different follow-ups was compared between groups by use of t-tests, and effect sizes were calculated in terms of Cohen's $d$ [24].

Mixed-effect models for repeated measures were used to evaluate sleep quality over time during the follow-up period. The intention-to-treat principle was applied, with the last observation carried forward for missing values. A sensitivity analysis was conducted for complete cases. The dependent variable was the sleep subscales, and the independent variables were baseline score of sleep quality, study group, follow-up time and interactions between study group and baseline sleep score as well as between study group and follow-up time.

To determine whether psychological distress and hot flushes modify the effect of MBSR on sleep quality, the mixed-effect models were adjusted for the interaction between baseline level of psychological distress and study group and the interaction between baseline score of hot flushes and study group, respectively.

Quantile regression was used to estimate the effect of MBSR on different subgroups of study participants. We used the Hubert sandwich estimator to calculate confidence intervals. Change in sleep problem index II score was the dependent

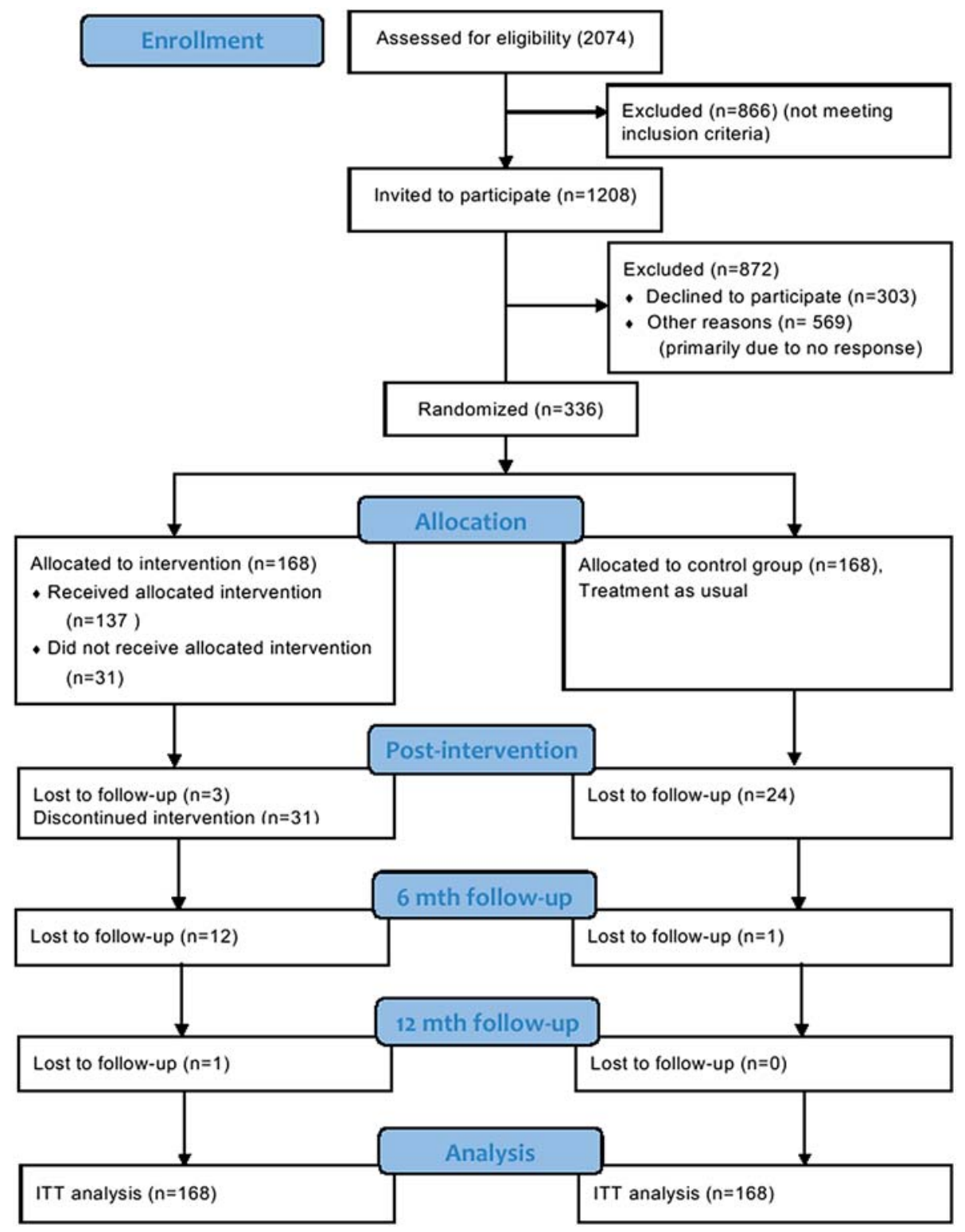

Figure 1. Numbers of study participants during the study period. ITT, intention-to-treat. 
variable, and baseline sleep score and study group were set as independent variables. Change was calculated in the quantile regression analyses as baseline measure minus follow-up measure. Consequently, a high change value represented a greater improvement in sleep. The regression coefficients for effect of study group represented the increase in change score in the MBSR group as compared with the control group. To test whether estimates of effects on the different percentiles of change were significantly different from one another, a Wald significance test was used.

All the statistical analyses were performed with SAS version 9.2. All hypotheses were two-sided, and the significance level was set to $\mathrm{p}<0.05$.

\section{Results}

\section{Participants}

Figure 1 is the flow diagram of the process of enrolment, intervention allocation and follow-up in the MICA trial. At 12 months of follow-up, 121 women $(72 \%)$ in the MBSR group and $143(85 \%)$ controls completed the sleep scale and were included in further analyses. Cases and controls did not differ statistically significantly at baseline for any of the measured variables (Table I); hence, the randomization procedure was considered balanced.

\section{Mean sleep scores}

Overall, sleep quality improved between baseline and all follow-up times in both the MBSR and the control group (Table II). After the intervention, the between-group difference in mean scores for sleep disturbance, sleep problem index I and sleep problem index II reached statistical significance $(p=0.03)$, indicating better sleep quality in the MBSR group than in the control group (Table II). At the six- and 12-month follow-ups, there were no significant differences between the MBSR and the control group; because of low response rates for 'snoring', the effect on snoring was regarded as irrelevant. Intention-totreat analyses of the entire follow-up period showed that MBSR had no significant effect on sleep quality over time (all $\mathrm{p}$ values $>0.05$ ) (Table II).

The analysis of changes in sleep quality showed statistically significant between-group differences in sleep problem index II between baseline and postintervention $(p=0.05)$ and in somnolence between baseline and the six-month follow-up $(\mathrm{p}=0.02)$, indicating a greater improvement in sleep quality in the MBSR group than in the control group.

Table I. Baseline characteristics of participants in the randomized controlled trial.

\begin{tabular}{|c|c|c|c|}
\hline Characteristic & MBSR $n=168$ & Controls $\mathrm{n}=168$ & p-value* \\
\hline Age at operation [mean, years (SD)] & $53.9(10.1)$ & $54.4(10.5)$ & 0.66 \\
\hline Time since diagnosis [mean, months (SD)] & $7.5(5.0)$ & $7.9(5.1)$ & 0.49 \\
\hline \multicolumn{4}{|l|}{ Breast cancer stage [n (\%)] } \\
\hline I & $51(30.4)$ & $64(38.1)$ & \multirow{3}{*}{0.06} \\
\hline II & $109(64.9)$ & $101(60.1)$ & \\
\hline III & $8(4.8)$ & $3(1.8)$ & \\
\hline \multicolumn{4}{|l|}{ Treatment $[\mathrm{n}(\%)]$} \\
\hline \multicolumn{4}{|l|}{ Allocated to chemotherapy } \\
\hline Yes & $78(46.4)$ & $82(48.8)$ & \multirow{3}{*}{0.93} \\
\hline No & $65(38.7)$ & $67(39.9)$ & \\
\hline Unknown & $25(14.9)$ & $19(11.3)$ & \\
\hline \multicolumn{4}{|l|}{ Allocated to radiotherapy } \\
\hline Yes & $125(74.4)$ & $145(86.3)$ & \multirow{3}{*}{0.5} \\
\hline No & $37(22.0)$ & $21(12.5)$ & \\
\hline Unknown & $6(3.6)$ & $2(1.2)$ & \\
\hline \multicolumn{4}{|l|}{ Allocated to hormonal therapy } \\
\hline Yes & $91(54.2)$ & $88(52.4)$ & \multirow{3}{*}{0.38} \\
\hline No & $50(29.8)$ & $60(35.7)$ & \\
\hline Unknown & $27(16.1)$ & $20(11.9)$ & \\
\hline \multicolumn{4}{|l|}{$\begin{array}{l}\text { Charlson comorbidity index at date of } \\
\text { diagnosis }[\mathrm{n}(\%)]\end{array}$} \\
\hline 0 & $146(86.9)$ & $145(86.3)$ & \multirow{3}{*}{0.83} \\
\hline 1 & $18(10.7)$ & $18(10.7)$ & \\
\hline$\geq 2$ & $4(2.4)$ & $5(3.0)$ & \\
\hline Married [n (\%)] & $123(73.2)$ & $120(71.4)$ & 0.72 \\
\hline Further and higher education [n (\%)] & $131(78.0)$ & $128(76.2)$ & 0.84 \\
\hline Hot flush score [mean (SD)] & $6.10(12.65)$ & $6.95(11.98)$ & 0.53 \\
\hline Psychological distress [mean (SD)] & $0.59(0.43)$ & $0.58(0.37)$ & 0.72 \\
\hline
\end{tabular}

*MBSR group compared with control group by t-test. 
The effect sizes were, however, small $($ all $<0.3$ ) (Table III).

\section{Quantile regression analysis}

Overall, the MBSR group had higher values for change, indicating more improvement in sleep problem index II, than the control group (Figure 2). A statistically significant effect for sleep problem index II was observed only on the 25 th percentile change (Figure 2), the values being mainly $<0$ for all baseline values and particularly between the baseline scores 18.33 and 42.67, representing the lower and upper quartiles, respectively (Figure 3 ). As a consequence, the 25th percentile change mainly reflected women with increased sleep problems between baseline and post-intervention. Our results therefore indicate that women who participated in MBSR had a significantly smaller increase in sleep problems than the control group. Comparison of estimates of the effect of study group, however, showed no statistically significant differences between the 25 th, 50 th and 75th percentile change for sleep problem index II $(p>0.16)$. Thus, the effect on the 25 th percentile was not significantly greater than that on the other percentiles. MBSR had a small effect for all percentiles, but this did not reach statistical significance for the 50th and 75th percentile (Figure 2).

No statistically significant between-group differences were observed for any percentile of change between baseline and the 12-month follow-up for sleep problem index II (results not shown).

\section{Effect modification}

In our analysis of effect modification, neither baseline level of psychological distress nor hot flushes modified the effect of MBSR on sleep quality after adjustment of mixed-effect models for interaction with distress and hot flushes, respectively (results not shown).

\section{Discussion}

In this study of sleep quality, a secondary outcome of the MICA trial (NCT00990977), MBSR was found to have small, short-term effects on sleep problems, with no long-term effects on sleep quality. Overall, this result is similar to those of previous studies of the effects of MBSR on sleep quality among breast cancer patients. Lengacher et al. (2011) [16], who studied 84 breast cancer patients in a randomized controlled trial, found a betweengroup difference for drowsiness but not for sleep disturbance after the intervention. In the MICA trial, however, a significant effect was found on sleep 


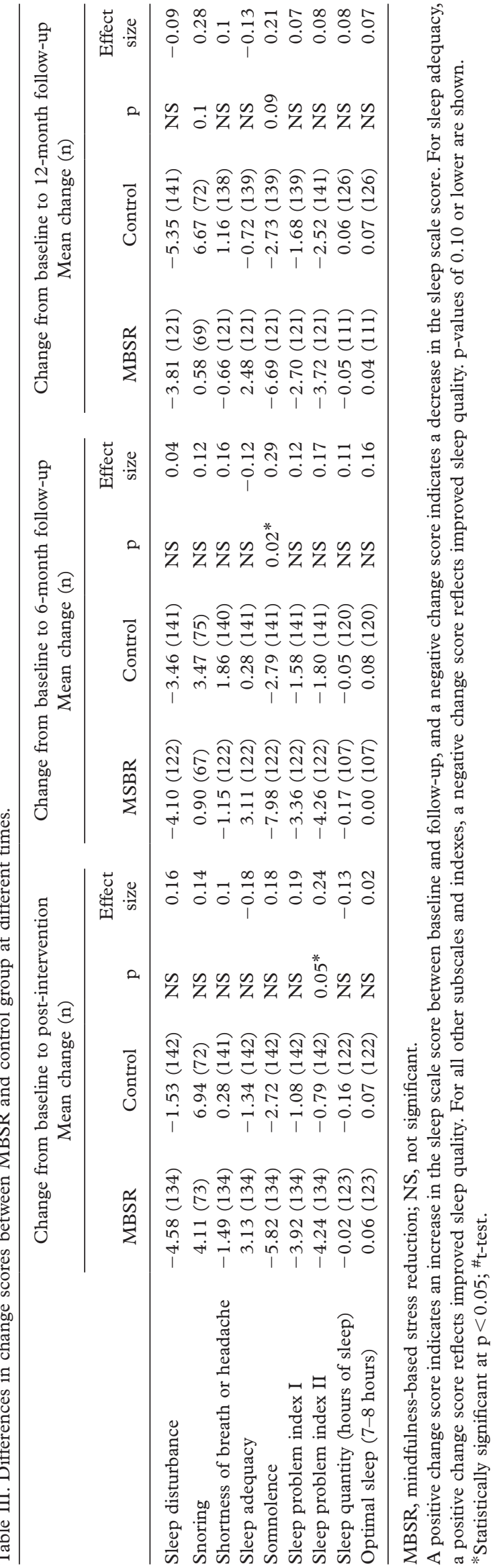

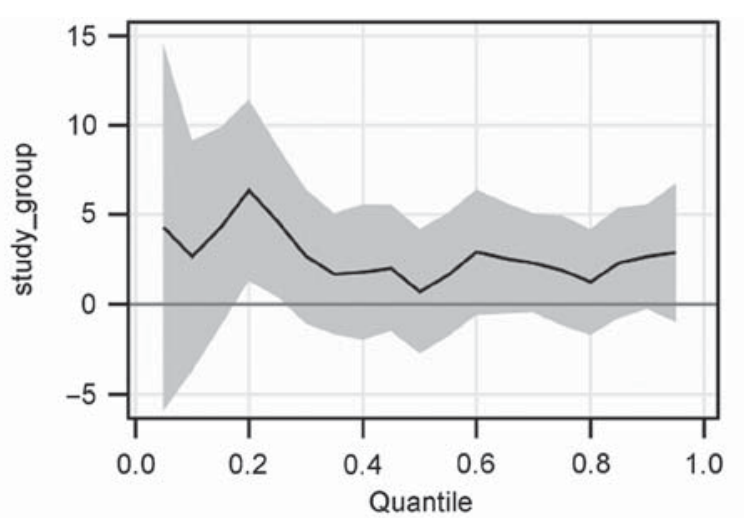

\begin{tabular}{|l|c|c|c|}
\hline Quantile & $\mathbf{2 5}^{\text {th }}$ & $\mathbf{5 0}^{\text {th }}$ & $\mathbf{7 5}^{\text {th }}$ \\
\hline Study group & $4.630^{*}$ & 0.694 & 1.871 \\
\hline
\end{tabular}

*significant effect, $p<0.05$.

Figure 2. Change in sleep problem index II between baseline and post-intervention. Estimated quantile regression coefficients and $95 \%$ confidence intervals (grey areas) for changes in sleep problem index II between baseline and post-intervention. The table shows the estimated quantile regression coefficients for the 25th, 50th and 75 th quantile. The values shown for the study group are for cases, as the controls were used as reference.

disturbance but not on somnolence. Both studies showed an effect on sleep quality, but not on the same parameters. Shapiro et al. (2003) [15] found no between-group difference in sleep quality at a nine-month follow-up $(n=63)$ in their quasiexperimental study. We also found no betweengroup differences in the intention-to-treat analysis of the entire follow-up period of 12 months. This suggests that MBSR has no significant long-term effects on sleep quality among breast cancer patients.

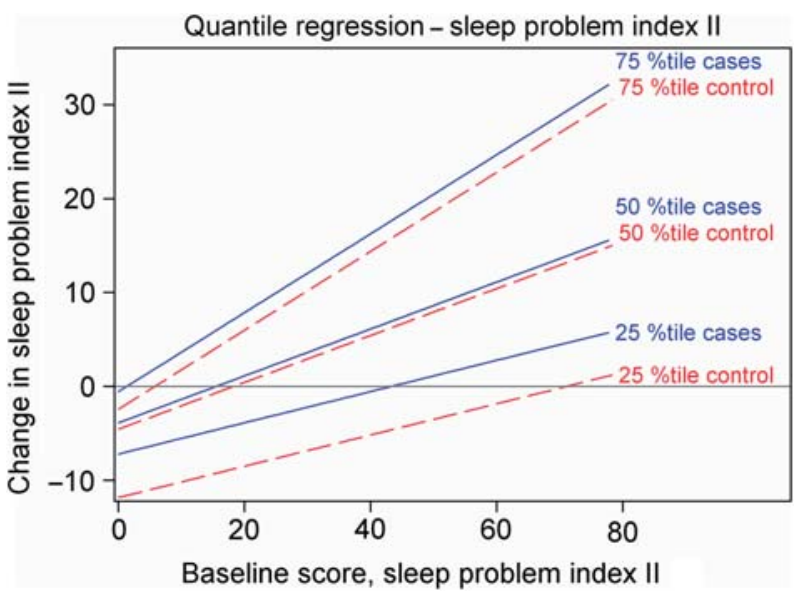

Figure 3. Quantile regression fit plot for change in sleep problem index II between baseline and post-intervention. The slopes of the lines are defined by the estimated quantile regression coefficient for baseline score. The estimated quantile regression coefficients of the study group determine the vertical difference between the lines representing cases and controls at a given percentile. 
The effect of MBSR on sleep quality was small, and we did not find any effect modification by distress and hot flushes. Further evaluations of modification of MBSR effects are recommended, to elucidate possible mechanisms by which MBSR could affect sleep quality [18].

Quantile regression analyses revealed a statistically significant effect on women in the 25 th percentile change of sleep problem index II (combined measure of sleep disturbance, sleep adequacy, awakening with shortness of breath or headache, and daytime somnolence) after the intervention. The 25th percentile mainly represented participants who had poorer sleep quality after the intervention. Thus, the finding of a statistically significant effect among participants with increased sleep problems might indicate that MBSR reduced the risk for developing sleep problems in this population. The effect of MBSR on the 25 th percentile change was not, however, statistically significantly higher than the effect on the 50th and 75 th percentile. Thus it cannot be firmly concluded that the effect of MBSR was greater for the 25th percentile change in this study; MBSR may have had a similar effect on all subgroups. No significant effects were found in the change between baseline and the 12-month follow-up in quantile regression, supporting the conclusion that MBSR had no long-term effect on sleep quality among the breast cancer patients in this study.

No significant difference was found between participants who completed the study and those who dropped out with regard to baseline sleep problems, indicating that attrition bias was not a reason for the non-significant effects of MBSR on sleep quality at follow-up. Few sleep problems at baseline might have diluted any effect of the intervention. The baseline level of sleep problems was not notably different from the available norm in the USA [21]. Future studies of the effect of MBSR on sleep quality in a population selected on the basis of baseline sleep problems are recommended, allowing for evaluation of whether MBSR can potentially be used as a treatment of sleep problems. The low prevalence of sleep problems in this study might reflect the fact that women were included up to 18 months after surgery, as breast cancer patients usually report more sleep problems closer to the time of diagnosis and surgery $[25,26]$. Another potential reason for the few sleep problems at baseline could be self-selection in volunteering to participate in the MICA study. A comparison of those who refused and those who participated showed that the latter were younger, had a less recent diagnosis and had a higher level of education than those who refused to participate [19]. Thus, those who refused to participate may have had more sleep problems, especially as they had received their diagnoses more recently. However, the motivation of participants in psychological interventions is crucial for compliance and for effects. Our initial finding of some effect of MBSR on sleep problems among breast cancer patients might increase the motivation of those with poor sleep quality to participate in future trials.

Treatment of sleep problems was not a specific aim of the original MICA trial. Hence, the lack of significant long-term effects of the MBSR intervention on sleep quality might be due to the fact that the aim of the intervention was not to treat sleep problems. Other researchers modified the MBSR program by adding education in sleep hygiene in a small study of non-cancer patients with insomnia [27]. The identification in our study of an effect on sleep quality post-intervention might rather suggest that booster sessions should be provided to maintain the effects of MBSR and promote long-term practice of mindfulness, which might ensure long-term effects on sleep quality. Adherence was assessed from training logs in the MICA trial, but the response rates were low, decreasing the validity of the information. Research on continued practice of mindfulness after MBSR will be needed to evaluate long-term adherence to practice.

Both participants and the control group reported improved sleep quality over time; therefore, time itself might have a substantial effect on sleep quality. This conclusion is in line with the finding of a higher prevalence of sleep problems in cancer patients assessed closer to the time of diagnosis and treatment, whereafter it declined. In general, patients with severe sleep problems, i.e. those who fulfil the diagnostic criteria of insomnia, are at high risk for chronic insomnia. Such individuals should be identified and targeted for treatment $[28,29]$.

\section{Limitations and advantages of the study}

Owing to the study design, with a control group receiving treatment as usual, the effects of MBSR on sleep quality could have been due to effects of additional attention from professionals or effects of meeting regularly with other cancer patients [30]. Therefore, further studies with control for such effects should be conducted to compare the effect of MBSR with that of interventions of the same intensity and format but without specific mindfulness elements.

Sleep quality was measured using the Medical Outcome Study sleep scale. This scale has not been validated for breast cancer patients and no cut-off values for significant sleep problems have been established. While it is an advantage that sleep quality was assessed on a sleep scale and not as a single item, as 
often done in previous studies, future studies should apply a validated measure or sleep diaries in order to allow for conclusions regarding the clinical significance of identified effects.

The design of the MICA trial was more suitable than that of previous studies on MBSR and sleep quality in cancer patients. The trial had a randomized controlled design and a large number of participants who were well-defined with regard to time since diagnosis (3-18 months). Furthermore, specific efforts were made to ensure instructor compliance with the original MBSR program, to ensure its integrity. None of the previous trials had a follow-up period as long as 12 months. With the advanced statistical methods used, the MICA study increases the knowledge regarding longer-term effects of MBSR on sleep quality among breast cancer patients.

The broad inclusion criteria and the minimal exclusion criteria in combination with systematic invitation to the MICA trial increase the generalizability of the results. Conversely, self-selection of participants might have decreased the generalizability, motivation and engagement of participants are crucial in MBSR interventions as the sample reflects the current BC sample and inclusion bias has been reduced.

\section{Conclusion}

In this population-based study evaluating MBSR on the secondary outcome sleep quality, small statistically significant effects were found post-intervention. However, the level of sleep problems at baseline was low, leaving little room for improvement or significant effects, and after 12 months' follow-up there was no statistically significant between-group effect of MBSR. Thus the sustainability of the effects of the intervention on sleep quality among breast cancer patients is questionable. Consequently, more studies of MBSR and its long-term effect on sleep quality and the burden of sleep problems in which participation is restricted to patients with significant sleep problems are recommended.

Declaration of interest: The authors report no conflicts of interest. The authors alone are responsible for the content and writing of the paper.

This work was funded by the Danish Cancer Society; the Psychosocial Research Committee (Grant number R13-A640-09-S3) and the CAM Research Committee (Grant number UP7001), University of Copenhagen; Multidisciplinary CAMresearch (Grant number 603-44-204/SD), Danish Cancer Research Foundation (Grant number 50-082008) and the Danish Cancer Society Research Centre.

\section{References}

[1] NORDCAN. NORDCAN projektet. [cited 2012 August 02]. Available from: http://www-dep iarc fr/NORDCAN/DK/ frame asp 2012.

[2] Pinto AC, de Azambuja E. Improving quality of life after breast cancer: Dealing with symptoms. Maturitas 2011;70: 343-8.

[3] Savard J, Morin CM. Insomnia in the context of cancer: A review of a neglected problem. J Clin Oncol 2001;19:895-908.

- [4] Davidson JR, MacLean AW, Brundage MD, Schulze K. Sleep disturbance in cancer patients. Soc Sci Med 2002;54: 1309-21.

- [5] Savard J, Ivers H, Villa J, Caplette-Gingras A, Morin CM. Natural course of insomnia comorbid with cancer: An 18-month longitudinal study. J Clin Oncol 2011;29:3580-6.

- [6] Savard J, Simard S, Blanchet J, Ivers H, Morin CM. Prevalence, clinical characteristics, and risk factors for insomnia in the context of breast cancer. Sleep 2001;24: 583-90.

[7] Colagiuri B, Christensen S, Jensen AB, Price MA, Butow $\mathrm{PN}$, Zachariae R. Prevalence and predictors of sleep difficulty in a national cohort of women with primary breast cancer three to four months postsurgery. J Pain Symptom Manage 2011;42:710-20.

- [8] Davidson JR, MacLean AW, Brundage MD, Schulze K. Sleep disturbance in cancer patients. Soc Sci Med 2002; 54:1309-21.

- [9] Vargas S, Wohlgemuth WK, Antoni MH, Lechner SC, Holley HA, Carver CS. Sleep dysfunction and psychosocial adaptation among women undergoing treatment for nonmetastatic breast cancer. Psychooncology 2010;19:669-73.

[10] Fortner BV, Stepanski EJ, Wang SC, Kasprowicz S, Durrence $\mathrm{HH}$. Sleep and quality of life in breast cancer patients. J Pain Symptom Manage 2002;24:471-80.

[11] Davidson JR, Feldman-Stewart D, Brennenstuhl S, Ram S. How to provide insomnia interventions to people with cancer: Insights from patients. Psychooncology 2007;16:1028-38.

[12] Kabat-Zinn J. Full catastrophe living. How to cope with stress, pain and illness using mindfulness meditation. 15th anniversary edition. London: Piatkus; 2004.

[13] Piet J, Würtzen H, Zachariae R. The effect of mindfulnessbased therapy on symptoms of anxiety and depression in adult cancer patients and survivors: A systematic review and metaanalysis. J Consult Clin Psychol 2012;80:1007-20.

[14] Carlson LE, Garland SN. Impact of mindfulness-based stress reduction (MBSR) on sleep, mood, stress and fatigue symptoms in cancer outpatients. Int J Behav Med 2005;12: 278-85.

[15] Shapiro SL, Bootzin RR, Figueredo AJ, Lopez AM, Schwartz GE. The efficacy of mindfulness-based stress reduction in the treatment of sleep disturbance in women with breast cancer: An exploratory study. J Psychosom Res 2003;54:85-91.

- [16] Lengacher CA, Reich RR, Post-White J, Moscoso M, Shelton MM, Barta M, et al. Mindfulness based stress reduction in post-treatment breast cancer patients: An examination of symptoms and symptom clusters. J Behav Med 2012;35: 86-94.

[17] Würtzen H, Dalton S, Christensen J, Andersen KK, Elsass $\mathrm{P}$, Flyger $\mathrm{H}$, et al. Who participates in a randomized trial of mindfulness-based stress reduction (MBSR) after breast cancer? A study of factors associated with enrollment among Danish breast cancer patients. Psychooncology 2012 May 16. doi: 10.1002/pon.3094.

[18] Carmody JF, Crawford S, Salmoirago-Blotcher E, Leung K, Churchill L, Olendzki N. Mindfulness training for coping 


\section{S. R. Andersen et al.}

with hot flashes: Results of a randomized trial. Menopause 2011;18:611-20.

[19] Würtzen H, Dalton SO, Andersen KK, Elsass P, Flyger HL, Sumbundu A, et al. Mindfulness significantly reduces selfreported levels of anxiety and depression: Results of a randomised controlled trial among 336 Danish women treated for stage I-III breast cancer, Eur J Cancer (2012), http://dx.doi. org/10.1016/j.ejca.2012.10.030 (in press).

[20] [20] Hays RD, Stewart AL. Sleep measures. In: Stewart AL, Ware JE, editors. Measuring functioning and well-being. Durham and London: Duke University Press; 1992. p. 235-59.

- [21] Hays RD, Martin SA, Sesti AM, Spritzer KL. Psychometric properties of the Medical Outcomes Study Sleep measure. Sleep Med 2005;6:41-4.

[22] Olsen LR, Mortensen EL, Bech P. The SCL-90 and SCL$90 \mathrm{R}$ versions validated by item response models in a Danish community sample. Acta Psychiatr Scand 2004;110:225-9.

[23] Sloan JA, Loprinzi CL, Novotny PJ, Barton DL, Lavasseur BI, Windschitl H. Methodologic lessons learned from hot flash studies. J Clin Oncol 2001;19:4280-90.

[24] Cohen J. Statistical power analysis for the behavioral sciences. 2nd ed. Hillsdale, NJ: Lawrence Erlbaum Associates; 1988.
[25] Cimprich B. Pretreatment symptom distress in women newly diagnosed with breast cancer. Cancer Nurs 1999; 22:185-94.

[26] Kenefick AL. Patterns of symptom distress in older women after surgical treatment for breast cancer. Oncol Nurs Forum 2006;33:327-35.

[27] Gross CR, Kreitzer MJ, Reilly-Spong M, Wall M, Winbush NY, Patterson R, et al. Mindfulness-based stress reduction versus pharmacotherapy for chronic primary insomnia: A randomized controlled clinical trial. Explore (NY) 2011;7:76-87.

[28] Kjaer TK, Johansen C, Ibfelt E, Christensen J, Rottmann N, Hoybye MT, et al. Impact of symptom burden on health related quality of life of cancer survivors in a Danish cancer rehabilitation program: A longitudinal study. Acta Oncol 2011;50:223-32.

[29] Thorsen L, Gjerset GM, Loge JH, Kiserud CE, Skovlund E, Flotten T, et al. Cancer patients' needs for rehabilitation services. Acta Oncol 2011;50:212-22.

[30] Hansen HP, Tjornhoj-Thomsen T, Johansen C. Rehabilitation interventions for cancer survivors: The influence of context. Acta Oncol 2011;50:259-64. 